\title{
Syntheses and Crystal Structures of $\mathrm{PbSbO}_{2} \mathrm{Br}, \mathrm{PbSbO}_{2} \mathrm{I}$, and $\mathrm{PbBiO}_{2} \mathrm{Br}$
}

\author{
Arno Pfitzner* ${ }^{[a]}$ and Patrick Pohla ${ }^{[a]}$ \\ Dedicated to Professor Gerd Meyer on the Occasion of His 60th Birthday
}

Keywords: Lead; Antimony; Bismuth; Oxide halide

\begin{abstract}
Transparent single crystals of $\mathrm{PbSbO}_{2} \mathrm{Br}$ (green), $\mathrm{PbSbO}_{2} \mathrm{I}$, and $\mathrm{PbBiO}_{2} \mathrm{Br}$ (yellow) were obtained by solid state reactions of stoichiometric amounts of $\mathrm{PbO}, \mathrm{Pn}_{2} \mathrm{O}_{3}(P n=\mathrm{Sb}, \mathrm{Bi})$ and $P n X_{3}(X=\mathrm{Br}$, I). The crystal structures were determined from single-crystal $\mathrm{X}$-ray data. The title compounds crystallize tetragonally in the space group I4/mmm (No. 139): Lattice constants and refinement values are: $\mathrm{PbSbO}_{2} \mathrm{Br}: a=3.9463(3), c=12.849(1) \AA, V=200.10(3) \AA^{3}$, and $Z=$ 2, $R_{1}=0.0236$, and $w R_{2}=0.0513 . \mathrm{PbSbO}_{2} \mathrm{I}: a=4.0074(3), c=$
\end{abstract}

13.627(2) $\AA, V=218.84(3) \AA^{3}$, and $Z=2, R_{1}=0.0244$, and $w R_{2}=$ 0.0538. $\mathrm{PbBiO}_{2} \mathrm{Br}: a=3.9818(2), c=12.766(2) \AA, V=202.39(4) \AA^{3}$, and $Z=2, R_{1}=0.0276$, and $w R_{2}=0.0715$. The compounds are isotypic and crystallize in the anti- $\mathrm{ThCr}_{2} \mathrm{Si}_{2}$ structure type with lead and $P n$ statistically disordered on one common position. In case of $P n=\mathrm{Sb}$ a slight separation of the positions of the cations becomes obvious. Optical bandgaps were determined by UV/Vis spectroscopy. They are $2.67 \mathrm{eV}\left(\mathrm{PbSbO}_{2} \mathrm{Br}\right), 2.48 \mathrm{eV}\left(\mathrm{PbSbO}_{2} \mathrm{I}\right)$, and $2.47 \mathrm{eV}\left(\mathrm{PbBiO}_{2} \mathrm{Br}\right)$.

\section{Introduction}

The minerals Nadorite $\mathrm{PbSbO}_{2} \mathrm{Cl}$ and Perite $\mathrm{PbBiO}_{2} \mathrm{Cl}$ and their homologous bromide and iodide compounds have been in focus of research since many years. Perite was first found in Langban, Sweden in 1960. The crystal structure of Perite was first solved by Gillberg in 1960 [1]. He determined orthorhombic symmetry for Perite. However, in 1976 a Perite with tetragonal symmetry was found in Australia [2]. Nadorite was first described in 1941 by Sillén with orthorhombic symmetry [3], the crystal structure is described in [4]. The first report of a synthetic analogue of Nadorite was not until 2002 [5]. It was tried to synthesize the homologues compounds with bromine and iodine since the first discovery of Perite and Nadorite. The first characterization of these synthetic compounds from X-ray powder data was reported in 1970 [6]. In 1985 the single-crystal X-ray structure of $\mathrm{PbBiO}_{2} \mathrm{I}$ was determined [7]. Very recently $\mathrm{PbBiO}_{2} \mathrm{Br}$ was described as a catalyst for photocatalytic degradation of organic dyes [8]. Surprisingly, there are no single crystal structure data of this compound available in literature. However, it is desirable to have a good knowledge of structural data in case of compounds, which are discussed as promising heterogeneous catalysts in order to get some idea about the catalytic processes. In addition, the question arises for a structural differentiation of $\mathrm{Pb}^{2+}$ and $\mathrm{Sb}^{3+}$ located on one crystallographic position. As observed earlier one finds a clear tendency of $\mathrm{Sb}^{3+}$ to prefer a small number of short contacts to counterions and in addition to have a greater number of long

\footnotetext{
* Prof. Dr. A. Pfitzner

Fax: +49-941-943-814551

E-Mail: arno.pfitzner@chemie.uni-regensburg.de

[a] Institut für Anorganische Chemie

Universität Regensburg

93040 Regensburg, Germany
}

distances to further counterions. The gap between such short and long distances differs significantly in case of isotypic $\mathrm{Bi}^{3+}$ compounds, i.e., the distances vary in a much smaller range, see [9-11] for a discussion. Herein, we report on the synthesis and single-crystal X-ray structure determination of $\mathrm{PbBiO}_{2} \mathrm{Br}$ and its homologues compounds $\mathrm{PbSbO}_{2} \mathrm{Br}$ and $\mathrm{PbSbO}_{2} \mathrm{I}$.

\section{Results and Discussion}

$\mathrm{PbSbO}_{2} \mathrm{Br}, \mathrm{PbSbO}_{2} \mathrm{I}$, and $\mathrm{PbBiO}_{2} \mathrm{Br}$ are isotypic and crystallize tetragonally in the space group $I 4 / \mathrm{mmm}$ (No. 139) with two formula units per unit cell in the anti- $\mathrm{ThCr}_{2} \mathrm{Si}_{2}$ structure [12]. Crystallographic data and experimental details of the data collection are listed in Table 1.

Figure 1 shows the crystal structure of $\mathrm{PbPnO} \mathrm{O}_{2} X$ along [010]. The structures consist of metal oxide layers perpendicular to [001] separated by halide ions. This matches with a Sillén X1phase [13]. In the metal-oxide layer the metal position seems to be statistically occupied by lead and antimony, respectively and bismuth, in the ratio $1: 1$, which was confirmed by free refinement of the occupancies. This agrees with the model for cation ordering in Sillén X1-phases [14]. However, the assumption of a statistical distribution of lead and antimony on one single position leads to a non-balanced electron density in the final difference-Fourier synthesis, i.e., the most negative residues are about $4 \mathrm{e}^{-} \AA^{-3}$ located close to the $\mathrm{Pb} / \mathrm{Sb}$ position. An independent refinement of lead and antimony, respectively and bismuth, showed a displacement of the $P n$ atom along the $z$-axis towards the oxygen layer for the antimony-bearing compounds. The displacement is significant for the antimony compounds ( $\mathrm{PbSbO}_{2} \mathrm{Br}$ : $\left.0.311 \AA ; \mathrm{PbSbO}_{2} \mathrm{I}: 0.371 \AA\right)$ but in the range of error for $\mathrm{PbBiO}_{2} \mathrm{Br}$. This matches with the findings 
Table 1. Crystallographic data for $\mathrm{PbSbO}_{2} \mathrm{Br}, \mathrm{PbSbO}_{2} \mathrm{I}$ and $\mathrm{PbBiO}_{2} \mathrm{Br}$ [23].

\begin{tabular}{|c|c|c|c|}
\hline Empirical formula & $\mathrm{PbSbO}_{2} \mathrm{Br}$ & $\mathrm{PbSbO}_{2} \mathrm{I}$ & $\mathrm{PbBiO}_{2} \mathrm{Br}$ \\
\hline Crystal system & \multicolumn{3}{|c|}{ tetragonal } \\
\hline Space group & \multicolumn{3}{|c|}{$I 4 / \mathrm{mmm}$} \\
\hline Lattice constants $a, c / \AA$ (powder refinement) & $3.9463(3), 12.849(1)$ & $4.0074(3), 13.627(2)$ & $3.9818(4), 12.766(2)$ \\
\hline$V / \AA^{3}, Z$ & $200.10(3), 2$ & $218.84(3), 2$ & $202.39(4), 2$ \\
\hline$\rho_{\mathrm{X}-\mathrm{ray}} / \mathrm{g} \cdot \mathrm{cm}^{-3}$ & 7.317 & 7.456 & 8.665 \\
\hline Diffractometer & \multicolumn{3}{|c|}{ STOE IPDS I } \\
\hline $2 \theta$-range $/{ }^{\circ}$ & $3.2 \leq 2 \theta \leq 53.12$ & $3.0 \leq 2 \theta \leq 49.7$ & $3.2 \leq 2 \theta \leq 53.12$ \\
\hline$\mu\left(\mathrm{Mo}-K_{\alpha}\right) / \mathrm{mm}^{-1}$ & 58.557 & 51.467 & 94.632 \\
\hline$T / \mathrm{K}$ & & 293 & \\
\hline Crystal size $/ \mathrm{mm}^{3}$ & $0.2 \times 0.17 \times 0.03$ & $0.23 \times 0.05 \times 0.08$ & $0.12 \times 0.14 \times 0.04$ \\
\hline Reflections (measured/unique) & 1467,84 & 1385,80 & 1541,86 \\
\hline$R_{\text {int }}$ & 0.0889 & 0.0658 & 0.1148 \\
\hline$R_{\sigma}$ & 0.0304 & 0.0247 & 0.0311 \\
\hline Structure solution & \multirow{2}{*}{\multicolumn{3}{|c|}{ SIR2004 [18] }} \\
\hline Structure refinement & & & \\
\hline$R_{1}\left(I>2 \sigma_{I}\right)$ & 0.0236 & 0.0244 & 0.0276 \\
\hline$R_{1}($ all $)$ & 0.0236 & 0.0244 & 0.0291 \\
\hline$w R_{2}\left(I>2 \sigma_{I}\right)$ & 0.0513 & 0.0538 & 0.0715 \\
\hline$w R_{2}$ (all) & 0.0513 & 0.0538 & 0.0724 \\
\hline Parameters & 12 & 12 & 9 \\
\hline GooF & 1.291 & 1.277 & 1.397 \\
\hline$\Delta \rho_{\max }, \Delta \rho_{\min } / \mathrm{e} \cdot \AA^{-3}$ & $+1.288,-1.440$ & $+0.808,-1.735$ & $+2.144,-1.390$ \\
\hline
\end{tabular}

described in [9]. It seems quite reasonable to find a slightly different coordination for $\mathrm{Sb}^{3+}$ as compared to $\mathrm{Pb}^{2+}$, whereas $\mathrm{Bi}^{3+}$ and $\mathrm{Pb}^{2+}$ can be described on one position with a mixed occupancy.

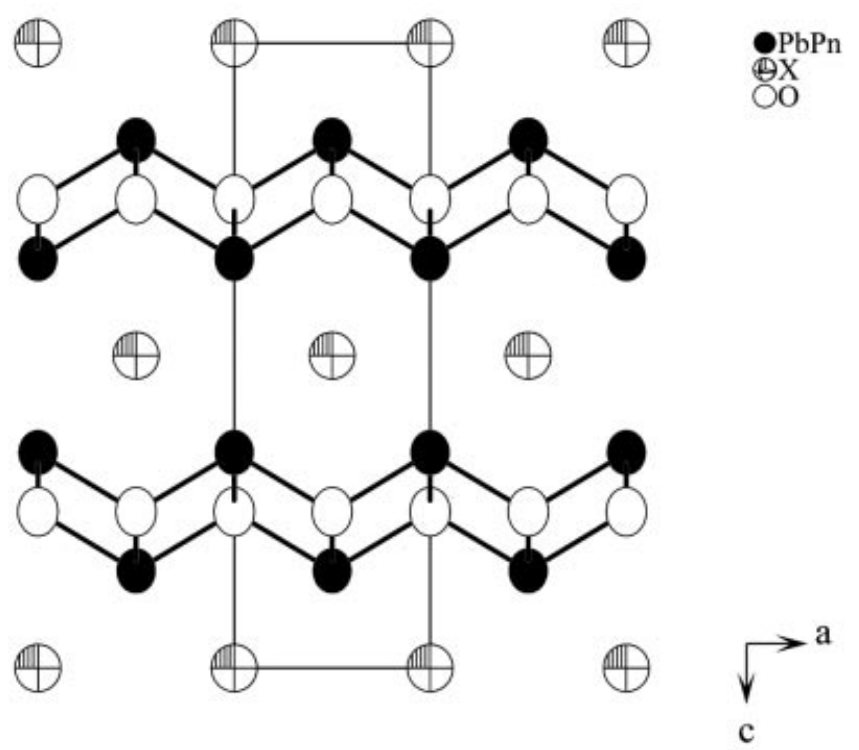

Figure 1. Crystal structure of $\mathrm{PbPnO} \mathrm{O}_{2} X(P n=\mathrm{Sb}, \mathrm{Bi} ; X=\mathrm{Br}$, I $)$ along [010]. The separation of the metal positions for $P n=\mathrm{Sb}^{3+}$ is not displayed. Ellipsoids correspond to a probability of $90 \%$.

Each oxygen atom is coordinated by four metal atoms with bond lengths $d(\mathrm{~Pb}-\mathrm{O})=2.400(1) \AA / d(\mathrm{Sb}-\mathrm{O})=2.237(2) \AA$ $\left(\mathrm{PbSbO}_{2} \mathrm{Br}\right), d(\mathrm{~Pb}-\mathrm{O})=2.428(8) \AA / d(\mathrm{Sb}-\mathrm{O})=2.240(1) \AA$ $\left(\mathrm{PbSbO}_{2} \mathrm{I}\right)$, and $d(\mathrm{~Pb} / \mathrm{Bi}-\mathrm{O})=2.3281(1) \AA\left(\mathrm{PbBiO}_{2} \mathrm{Br}\right)$. The resulting $\mathrm{OM}_{4}$-tetrahedra $(M=$ metal) are edge-sharing and form $M O$-layers perpendicular to [001], separated by halide ions. Each metal atom is surrounded by four oxygen and four halogen atoms in a longer distance forming the motif of a distorted tetragonal antiprism. The halogen atoms have a slightly distorted cubic environment of eight metal atoms. The degree of distortion is more significant in case of the antimony compounds. The compounds are isotypic to $\mathrm{PbBiO}_{2} \mathrm{I}$ [7], $\mathrm{Bi}_{2} \mathrm{O}_{2} \mathrm{Se}$ [15], a series of compounds with the composition $\left(M, \mathrm{Bi}_{2} \mathrm{O}_{2} X\right.$ $(M=$ alkaline earths, $X=\mathrm{Cl}, \mathrm{Br}, \mathrm{I})$ [16], and $M \mathrm{PbF}_{2} X(M=$ Li, Na, K) [17] (Table 2).

Table 2. Atom positions ${ }^{\mathrm{a})}$ and equivalent displacement parameters ${ }^{\mathrm{b})}$ for $\mathrm{PbSbO}_{2} \mathrm{Br}, \mathrm{PbSbO}_{2} \mathrm{I}$, and $\mathrm{PbBiO}_{2} \mathrm{Br}$.

\begin{tabular}{|c|c|c|c|c|c|c|}
\hline Atom & Wyck. & Occ. & $x$ & $y$ & $z$ & $U_{e q} / \AA^{2}$ \\
\hline \multicolumn{7}{|c|}{$\mathrm{PbSbO}_{2} \mathrm{Br}$} \\
\hline $\mathrm{Pb}$ & $4 e$ & 0.5 & 0 & 0 & $0.3563(1)$ & $0.027(1)$ \\
\hline $\mathrm{Sb}$ & $4 e$ & 0.5 & 0 & 0 & $0.3321(3)$ & $0.031(1)$ \\
\hline $\mathrm{Br}$ & $2 a$ & 1 & 0 & 0 & 0 & $0.033(1)$ \\
\hline $\mathrm{O}$ & $4 d$ & 1 & 0 & $1 / 2$ & $1 / 4$ & $0.047(2)$ \\
\hline \multicolumn{7}{|c|}{$\mathrm{PbSbO}_{2} \mathrm{I}$} \\
\hline $\mathrm{Pb}$ & $4 e$ & 0.5 & 0 & 0 & $0.3507(1)$ & $0.023(1)$ \\
\hline $\mathrm{Sb}$ & $4 e$ & 0.5 & 0 & 0 & $0.3235(2)$ & $0.019(1)$ \\
\hline $\mathrm{Br}$ & $2 a$ & 1 & 0 & 0 & 0 & $0.027(1)$ \\
\hline $\mathrm{O}$ & $4 d$ & 1 & 0 & $1 / 2$ & $1 / 4$ & $0.048(2)$ \\
\hline \multicolumn{7}{|c|}{$\mathrm{PbBiO}_{2} \mathrm{Br}^{\mathrm{c})}$} \\
\hline $\mathrm{Pb} / \mathrm{Bi}$ & $4 e$ & $0.5 / 0.5$ & 0 & 0 & $0.3445(1)$ & $0.029(1)$ \\
\hline $\mathrm{Br}$ & $2 a$ & 1 & 0 & 0 & 0 & $0.039(1)$ \\
\hline $\mathrm{O}$ & $4 d$ & 1 & 0 & $1 / 2$ & $1 / 4$ & $0.035(3)$ \\
\hline
\end{tabular}

a) Estimated standard deviations of the last significant digits in parantheses. b) $U_{e q}$ is defined as one third of the trace of the orthogonalized $U_{i j}$ tensor. c) Lead and bismuth are statistically disordered on one position in the ratio $1: 1$. 
Optical bandgaps of $2.67 \mathrm{eV} \quad\left(\mathrm{PbSbO}_{2} \mathrm{Br}\right), \quad 2.48 \mathrm{eV}$ $\left(\mathrm{PbSbO}_{2} \mathrm{I}\right)$, and $2.47 \mathrm{eV}\left(\mathrm{PbBiO}_{2} \mathrm{Br}\right)$ were calculated from UV/ Vis absorption spectra by extrapolation of the absorption edge to the base line. Figure 2 shows the absorption spectra of the title compounds.

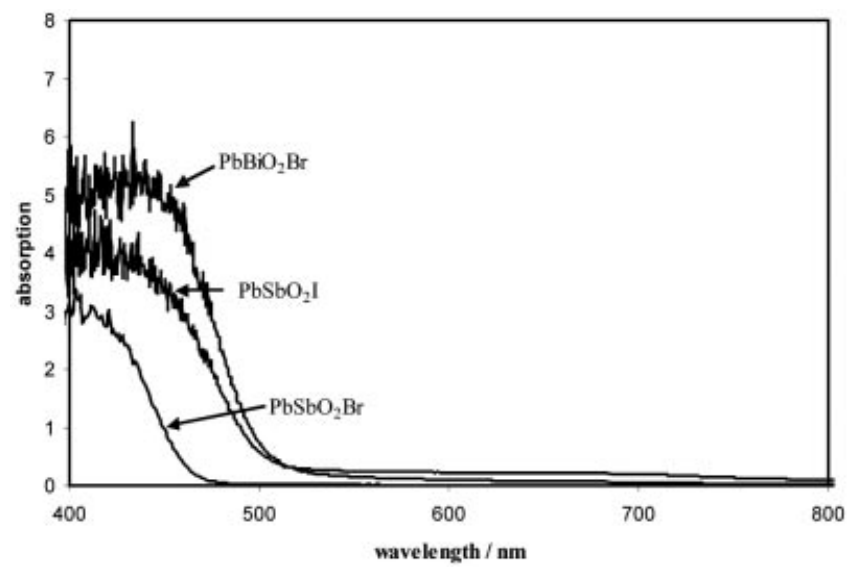

Figure 2. $\mathrm{UV} / \mathrm{Vis}$ spectra of $\mathrm{PbSbO}_{2} \mathrm{Br}, \mathrm{PbSbO}_{2} \mathrm{I}$, and $\mathrm{PbBiO}_{2} \mathrm{Br}$.

\section{Conclusions}

A closer inspection of the structural data of $\mathrm{PbSbO}_{2} \mathrm{Br}$ and $\mathrm{PbSbO}_{2} \mathrm{I}$ with the heavier homologues $\mathrm{PbBiO}_{2} \mathrm{Br}$ and $\mathrm{PbBiO}_{2} \mathrm{I}$ shows a slightly increasing unit cell volume as expected. However, the ratio $c$ : $a$ systematically decreases for about $2 \%$ in both cases. This compression of the crystal structures in case of the bismuth compounds might be caused by the different site occupation behaviour of $\mathrm{Pb}^{2+}$ and $\mathrm{Pn}^{3+}$ for $\mathrm{Pn}=\mathrm{Sb}^{3+}$ as compared to $P n=\mathrm{Bi}^{3+}$. It is certainly due to the preference of $\mathrm{Sb}^{3+}$ to form shorter bonds to the oxide ions and to further increase the distances to the halide ions as a consequence. For $\mathrm{Bi}^{3+}$ a different trend is observed, namely the formation of a greater number of contacts. This leads to an elongation of the shorter contacts. However, this seems to be crucial for the $c$ : $a$ ratio since the bonding interactions along [001] are increased by this behavior.

\section{Experimental Section}

$\mathrm{Pb} P n \mathrm{O}_{2} X$ with $P n=\mathrm{Sb}$, Bi and $X=\mathrm{Br}$, I were synthesized directly from $\mathrm{PbO}, \mathrm{Pn}_{2} \mathrm{O}_{3}$ and $\mathrm{Pn} \mathrm{X}_{3}$ in evacuated silica ampoules by annealing the corresponding $3: 1: 1$ mixtures at $500{ }^{\circ} \mathrm{C}$ for 4 months $\left(\mathrm{PbSbO}_{2} \mathrm{Br}\right)$, $550{ }^{\circ} \mathrm{C}$ for 12 days $\left(\mathrm{PbSbO}_{2} \mathrm{I}\right)$, and $650^{\circ} \mathrm{C}$ for 34 days $\left(\mathrm{PbBiO}_{2} \mathrm{Br}\right)$. The product consists of pale green powder and pale greenish transparent crystals $\left(\mathrm{PbSbO}_{2} \mathrm{Br}\right)$, yellow powder and yellow transparent crystals $\left(\mathrm{PbSbO}_{2} \mathrm{I}\right.$ and $\left.\mathrm{PbBiO}_{2} \mathrm{Br}\right)$. The purity of the products was confirmed by X-ray powder diffraction. All compounds are air stable.
Single crystal diffraction data of the title compounds were collected with a STOE IPDS I diffractometer equipped with a graphite monochromator and Mo- $K_{\alpha}$ radiation at room temperature. Numerical absorption corrections were performed with optimized crystal shapes using the X-SHAPE and X-RED programs [20,21]. The structures were solved by direct methods (SIR2004 [18]) and refined by full-matrix least-squares using SHELXL [19]. The final cycles included anisotropic displacement parameters for all atoms and an extinction parameter for the antimony compounds. The lattice constants were refined from X-ray powder diffraction data and used in the structure refinements.

Diffuse UV/Vis reflectance spectra were recorded with a Bruins Instruments Omega 20 spectrometer. Data were transferred to absorption spectra by the Kubelka-Munk method [22].

\section{References}

[1] M. Gillberg, Ark. Mineral. Geol. 1960, 2, 565.

[2] P. J. Bridge, Mineral. Magn. 1976, 40, 537.

[3] L. G. Sillén, Z. Anorg. Allg. Chem. 1941, 246, 420.

[4] G. Giuseppetti, C. Tadini, Periodico. di Mineralogia. 1973, 42, 335.

[5] Y. Porter, P. S. Halasyamani, Z. Naturforsch. 2002, 57b, 360.

[6] A. Deschanvres, J. Gallay, J.-M. Hunout, M.-T. Thiault, C. Victor, C R. Acad. Sci. Paris 1970, 270, 696.

[7] J. Ketterer, V. Krämer, Mater. Res. Bull. 1985, 20, 1031.

[8] Z. Shan, W. Wang, X. Lin, H. Ding, F. Huang, J. Solid State Chem. 2008, 181, 1361.

[9] A. Pfitzner, D. Kurowski, Z. Kristallogr. 2000, 215, 373.

[10] S. F. Matar, R. Weihrich, D. Kurowski, A. Pfitzner, V. Eyert, Phys. Rev. B 2005, 71, 235207.

[11] S. Lee, E. Fischer, J. Czerniak, N. Nagasundaram, J. Alloys Comp. 1993, 197, 1.

[12] Z. Ban, M. Sikirica, Acta Crystallogr. 1965, 18, 594.

[13] L. G. Sillén, Naturwissenschaften. 1942, 22, 318.

[14] D. O. Charkin, P. S. Berdonsov, V. A. Dolgikh, P. Lightfoot, J. Solid State Chem. 2003, 175, 316.

[15] P. Schmidt, O. Rademacher, H. Oppermann, S. Däbritz, Z. Anorg. Allg. Chem. 2000, 626, 1999.

[16] L. G. Sillén, Z. Anorg. Allg. Chem. 1939, 242, 41.

[17] J. F. Ackermann, Mater. Res. Bull. 1982, 17, 883.

[18] SIR2004, M. C. Burla, C. Rocco, M. Camalli, B. Benedetta, G. L. Cascarano, L. De Caro, C. Giacovazzo, G. Polidori, R. Spagna, J. Appl. Crystallogr. 2005, 38, 381 .

[19] SHELXL, G. M. Sheldrick, Acta Crystallogr., Sect. A 2008, 64, 112.

[20] X-SHAPE, Stoe \& Cie GmbH, Darmstadt, 1999.

[21] X-RED32, Stoe \& Cie GmbH, Darmstadt, 2004.

[22] P. Kubelka, F. Munk, Z. Techn. Physik. 1931, 593.

[23] Further details of the crystal structure investigation are available from the Fachinformationszentrum Karlsruhe, 76344 EggensteinLeopoldshafen, Germany (Fax: +49-7247-808-666, E-Mail: crysdata@fiz-karlsruhe.de) referring to number CDS-380313 $\left(\mathrm{PbSbO}_{2} \mathrm{Br}\right), \mathrm{CDS}-380314\left(\mathrm{PbSbO}_{2} \mathrm{I}\right), \mathrm{CDS}-380312\left(\mathrm{PbBiO}_{2} \mathrm{Br}\right)$, name of the authors and citation of the paper.

Received: March 23, 2009 Published Online: May 19, 2009 